\title{
1 Investigation into the bond strength of bitumen-fibre mastic
}

\section{Abstract}

3 The loss of bond strength in road pavement surfacing due to high traffic loads or

4 moisture is a recurring problem, creating distresses such as ravelling, fatigue and

5 rutting. It is, therefore, important to find a way to prevent or at least delay the loss of

6 bond strength in asphalt mixtures. Such an improvement would lead to longer service

7 life and a more comfortable drive for road users. This study describes how the pneumatic

8 adhesion tensile testing instrument (PATTI) was used to examine the mechanism by

9 which fibres influence the pull-off tensile strength of asphalt mastic. This study assesses

10 the potential for chemical modification of the binder due to the presence of fibres, by

11 means of work of cohesion and work of adhesion calculations, based on surface energy

12 parameters and a binder drainage test. The study also evaluates the influence of

13 different filler-bitumen ratios and fibre percentages on pull-off tensile strength. The test

14 results indicate that the fibres enhance the pull-off tensile strength of the mastic, in

15 addition to changing the failure mode from cohesive to hybrid, implying an improvement

$\mathbf{1 6}$ in the cohesive strength of the mastic.

\section{1. Introduction}

18 The bond strength is considered an important property affecting asphalt mixture

19 performance. In an asphalt mixture, the aggregates are much stiffer and stronger than

$\mathbf{2 0}$ other components such as bituminous binder or mastic. Therefore, the possibility of

21 failure is expected to be very small through the aggregates themselves, while there is a

22 high possibility of failure in the material that bonds adjacent particles [1]. The loss of

23 strength of cohesive bonds within the bitumen itself is termed cohesive failure, and

24 adhesive failure is the breaking of the adhesive bonds between aggregate and bitumen

25 or mastic materials, mainly due to the effect of water or low temperatures [2]. Under the

26 effect of traffic loading forces, the aggregate particles tend to separate from each other.

27 As these forces increase, failure occurs at the interfaces between the aggregate and

28 mastic and/or inside the mastic film [3]. The loss of bond strength then compromises

29 pavement integrity, and this could lead to different pavement failure types such as

30 permanent deformation, ravelling and fatigue [4]. It is, therefore, important to

31 investigate this phenomenon and find a way to prevent or at least reduce such

32 deterioration in the bond strength. 
33 The pull-off tensile strength test is commonly used to investigate the bond strength and

34 failure type of a bitumen-aggregate mix. Past studies found that dry samples showed a

35 cohesive failure, while moisture-conditioned samples showed a hybrid or adhesive failure

$36[1,5,6]$. The physicochemical properties of bitumen and aggregate surfaces, their

37 surface energies, can be used to estimate the adhesive bond strength between the two

38 [7]. Also, adding modification (polymer, acid, anti-stripping additive) to bitumen will

39 influence the physicochemical properties and bond strength of bitumen [8].

40 Fibres have the potential to strengthen the bitumen phase, however studies have found

41 that different types and amounts of fibre strengthen the modified asphalt in different

42 ways $[9,10]$. Past studies [11-13] have suggested that some fibres can absorb the light

43 fraction of bitumen, in addition to the fact that adding fibres such as those of polyester,

44 polyacrylonitrile, lignin and asbestos change the optimum bitumen content of an asphalt 45 mixture. It is important to note that the mechanism of possible chemical modification of

46 binder in contact with fibres remains in large part unknown. The binder drainage test can

47 provide results that may help in understanding such modification.

48 This paper explores the influence of different types and percentages of fibre on the pull49 off tensile strength of bituminous mastic. The effect of different filler-bitumen ratios on

50 the pull-off tensile strength of fibre reinforced mastic is also investigated. To gain a

51 better understanding of the chemical effect of fibre on the binding properties of bitumen,

52 the work of cohesion and work of adhesion of drained binder, before and after mixing

53 with fibres are calculated from surface energy components. The relationship between the

54 work of cohesion and the pull-off tensile strength results of fibre reinforced mastic are

55 investigated. 


\section{2. Materials and experimental methods}

\subsection{Materials}

59

60

61

62

63

64

65

66

67

68

69

70

71

72

73

74

75

76

77

78

79

80

81

82

83

84

85

86

87

88

89

A combination of one penetration grade bitumen (40/60) [14], limestone filler with maximum size less than $0.063 \mathrm{~mm}$ and four fibre types (including two types of glass, cellulose and steel fibres recovered from tyres) were used. Table 1 lists the basic properties of these fibres. The glass fibres had two different lengths, 13 and $6 \mathrm{~mm}$, classified as glass-I and glass-s respectively. Micrographs of these four fibre types and the fibre reinforced mastic are shown in Figures 1 to 3 using a Cryo-scanning electron microscope (Quanta 200 3D (FEI)). Samples were coated with platinum (Pt) at $-160^{\circ} \mathrm{C}$ for 60 seconds at current of $10 \mathrm{~mA}$. Accelerating voltage used was $10 \mathrm{kV}$ for glass and cellulose and $15 \mathrm{kV}$ for steel fibre. These show the needle-like structure of glass fibres; the spongy and flexible nature of cellulose; and the thick steel fibres coated with mastic.

\subsection{Binder drainage test basket method}

In this work, the basket method [15] was used to measure the binder drainage of fibrereinforced mastic; $2.0 \%$ by volume of fibres in $80 \mathrm{~g}$ of binder. The resulting composite was placed into a steel mesh basket with sieve size 250 microns, which was then placed on a pre-wrapped tray in the oven at $160^{\circ} \mathrm{C}$ for 3 hours. Binder flowed and drained through the mesh into the pre-wrapped tray. After 3 hours the steel mesh basket and pre-wrapped tray were removed from the oven and the mesh basket separated from the pre-wrapped tray. Once cooled the weight of the tray and drained binder was measured and the weight of drained material (D) calculated in percent.

\subsection{Determination of asphaltene content}

Asphaltene content in the drained binders was measured according to BS 2000 [16]. In this method the drained binder was mixed with heptane and heated under reflux, separating the binder into three components (asphaltenes, waxy substances and inorganic material). The remaining material was extracted by chromatographic separation.

\subsection{Complex modulus test}

A Bohlin Gemini 200 (DSR) was used in this study for measuring the rheological properties of base and drained binder. Eleven testing frequencies ranging from 0.1 to $10.0(\mathrm{~Hz})$ were used in the DSR tests with nine testing temperatures between 30 and $70^{\circ} \mathrm{C}$ (at increments of $5^{\circ} \mathrm{C}$ ). 


\subsection{Pneumatic Adhesion Tensile Testing Instrument (PATTI) test}

91 The Pneumatic Adhesion Tensile Testing Instrument (PATTI) is used to measure the

92 cohesive and adhesive properties of a bitumen-aggregate system by measuring pull-off

93 strength. The PATTI consists of a portable pneumatic adhesion tester, piston and

94 reaction plate, air hose, camera and steel pull-out stub as shown in Figure 4. Aggregate

95 substrates and pull-stubs have to be cleaned and dried at room temperature for at least

9624 hours. Then, in order to remove any dust, the aggregate substrates and pull-stubs

97 were wiped carefully using a damp paper towel. After that, all aggregate substrates and

98 pull-stubs were placed in an oven at $80^{\circ} \mathrm{C}$ for one hour. The fibre reinforced mastic was

99 placed in an oven at $160^{\circ} \mathrm{C}$ for 30 minutes, and by this time the mastic was fluid enough

100 to coat the aggregate substrate. Then fibre reinforced mastic was poured onto the

101 aggregate substrate, and a pull-stub was immediately pressed into it to achieve good

102 mastic-aggregate adhesion [17]. Washers and three raised edges on the pull-stub are

103 used to control the film thickness.

104 Samples were left for 24 hours at room temperature before testing in order to allow

105 enough time for the aggregate and mastic to adhere and for the sample to reach the test

106 temperature. After the mastic and substrate had cooled down the excess mastic at the

107 edge of the pull-stub was carefully removed using a heated pallet knife. The test then

108 consists of applying an upward pressure to the asphalt mastic by movement of the pull-

109 out stub. Air pressure rate was fixed during the test in order to achieve repeatable

110 results. The pull-off tensile strength of mastic indicates when the applied pressure

111 exceeds the cohesive strength of the mastic or the adhesive bond strength between

112 mastic and aggregate. 


\subsection{Surface energy measurement}

114 Thermodynamic (adsorption) theory is widely accepted as an approach to explain the

115 interfacial adhesion of a liquid-solid contact. This theory is based on the principle that an

116 adhesive (the liquid) will adhere to a solid depending on the physical forces established

117 at the interface, so long as contact is maintained. The interfacial forces are van der

118 Waals and Lewis acid-base interactions. These forces are generally related to

119 fundamental thermodynamic quantities, in particular the surface free energies of the

120 materials involved [18]. The contact angles of binders and limestone aggregate were

121 measured by using three selected probe liquids, distilled water, glycerol and

122 diiodomethane [7].

\section{3. Surface energy}

124 According to past studies the cohesive and adhesive strengths of bitumen-aggregate

125 systems have been successfully determined from the surface free energy $(\boldsymbol{\gamma})[19,20]$.

126 Previous research investigated the technical criteria of test methods, such as accuracy,

127 precision and the ability to provide all three surface energy parameters and

128 recommended the Whilhelmy plate method (dynamic contact angle) for routine use [19].

129 Another study focused on evaluation of the resistance of asphalt mixtures to moisture

130 damage, through understanding the mechanisms that influence the surface energy of

131 aggregates and binders in addition to fracture behaviour of asphalt mixture. They found

132 that the ratio of the adhesive bond energy under dry conditions to the adhesive bond

133 energy under wet conditions is related to the asphalt mixture resistance to moisture

134 damage [20]. The surface free energy is a measure of the amount of energy needed to

135 form a unit area of new surface at the interface of the material [7].

136 The surface free energy $(\boldsymbol{\gamma})$ of a material comprises two components, a dispersive or

137 Lifshitz-van der Waals component $\left(\gamma^{L W}\right)$ of electrodynamic origin, and a polar

138 component $\left(\gamma^{A B}\right.$ ) caused by Lewis acid-base interactions [21] as shown in the following

139 equation:

$140 \quad \gamma^{\text {total }}=\gamma^{L W}+\gamma^{A B}$

141 The acid-base components can be subdivided into a Lewis acid parameter of surface free

142 energy $\left(\gamma^{+}\right)$and a Lewis base parameter of surface free energy $\left(\gamma^{-}\right)$as shown in the

143 following equation:

$144 \gamma^{A B}=2\left(\sqrt{\gamma^{+} \gamma^{-}}\right)$ 
145 By combining equations (1) and (2) the surface free energy $\left(\mathrm{mJ} / \mathrm{m}^{2}\right)$ or $\left(\mathrm{erg} / \mathrm{cm}^{2}\right)$ of a

146 material can be defined as:

$147 \gamma^{\text {total }}=\gamma^{L W+2\left(\sqrt{\gamma^{+} \gamma^{-}}\right)}$

\section{$148 \quad 3.1$ Work of cohesion}

149 The work of cohesion $\left(W_{c}\right)$ can be defined as the energy required to separate the liquid

150 or solid from itself and this depends on the attraction between molecules. The following

151 equation describes the work of cohesion [8]:

$152 W_{C}=2 \gamma^{\text {total }}$

\subsection{Work of adhesion}

154 The work of adhesion $\left(W_{a}\right)$ can be defined as the energy required to create new surfaces

155 between two materials (solid-liquid); therefore, work of adhesion represents the amount

156 of intermolecular interaction between two materials [22].

157 The work of adhesion is a dependent property of a solid-liquid pair. Accordingly the

158 interfacial surface free energy of a material (binder or aggregate) is the combination of

159 these non-polar (Lifshitz-van der Waals) and polar (Lewis acid/base) forces as shown in

160 the following equation:

$161 \gamma_{B A}=\gamma_{B A}^{L W}+\gamma_{B A}^{A B}$

162 Where B and A represent bitumen and aggregate, respectively. The adhesive Lifshitz-van

163 der Waals and Lewis acid/base bond strength can be determined by the following

164 equations, respectively [23].

$165 W^{L W}=\gamma_{B}^{L W}+\gamma_{A}^{L W}-\gamma_{B A}^{L W}$

$166 W^{A B}=\gamma_{B}^{A B}+\gamma_{A}^{A B}-\gamma_{B A}^{A B}$

167 The Lifshitz-van der Waals solid-liquid surface energy is described by the following

168 equations [23]:

169

$$
\gamma_{B A}^{L W}=\left(\sqrt{\gamma_{B}^{L W}}-\sqrt{\gamma_{A}^{L W}}\right)^{2}
$$


$170 \quad \gamma_{B A}^{A B}=2\left(\sqrt{\gamma_{B}^{+}}-\sqrt{\gamma_{A}^{+}}\right)\left(\sqrt{\gamma_{B}^{-}}-\sqrt{\gamma_{A}^{-}}\right)$

171 By substituting these two equations (8) and (9) into equations (6) and (7) the following

172 equation is obtained:

$173 W_{a}=2\left(\sqrt{\gamma_{B}^{L W} \gamma_{A}^{L W}}+\sqrt{\gamma_{B}^{+} \gamma_{A}^{-}}+\sqrt{\gamma_{B}^{-} \gamma_{A}^{+}}\right)$

174 Where $W^{L W}$ is the Lifshitz-van der Waals work of adhesion and $W^{A B}$ is the Lewis acid/base 175 work of cohesion.

176 In this paper the work of cohesion and work of adhesion, computed in this way, will be

177 used to interpret the pull-off test data.

178

179 4. Results and analysis

$180 \quad 4.1$ Binder drainage test results

181 The results of the binder drainage tests are the average of three values as shown in

182 Table 2. The results have low coefficient of variation, although higher for cellulose fibres

183 due to having a similar level of variability and lower average drained binder percentage.

184 The percentage of drained material reflects bitumen stability, which may be a function of

185 the mechanical interaction of the fibres in the binder and absorption/adsorption of

186 certain bitumen fractions by the fibres.

187 Cellulose fibre showed by far the highest stabilisation and absorption/adsorption effect

188 compared to the other fibre types, as expected due to the surface texture and large

189 surface area of cellulose fibre (see Table 1), giving high absorption and retention of

190 liquid media. Other fibre types (glass and steel) held lower amounts of bitumen. These

191 results may reflect the amount of bitumen adhering to the fibre surfaces. Samples of

192 base binder and drained binders were taken for analysis of asphaltene content and

193 surface energy components. 


\section{4.2 Asphaltene test results}

195 Asphaltenes are the bitumen fraction that is insoluble in low molecular weight paraffin,

196 such as propane, n-butane, n-pentane, n-heptane and n-hexane [24]. They are

197 relatively high in heteroatoms such as nitrogen, oxygen, carbon and hydrogen with

198 sulphur. Asphaltenes are the largest fraction of bitumen, responsible for the increase in

199 thickening, strength and stiffness of the bitumen and non-Newtonian rheological

200 behaviour [24]. This paper measured the influence of different fibre types on the

201 asphaltene content of base binder to explore the effect on bitumen chemistry of adding

202 fibres. A previous study indicated that high asphaltene content might have led to

203 increased cohesive and adhesive strength of base binder [25].

204 Two tests were performed for each fibre type, and the average asphaltene content is

205 reported in Table 3. The drained binders showed higher asphaltene content compared to

206 the base binder. As noted in the introduction, previous studies showed that fibres can

207 adsorb /absorb the light fraction of bitumen [11-13], and it is important to note that the

208 cellulose fibres retained over $50 \%$ of the bitumen in the drainage test while the other

209 fibres retained about $25 \%$, compared to $3 \%$ for the sample without fibres. Preferential

$\mathbf{2 1 0}$ adhesion of the lighter binder fraction would lead to higher asphaltene content in the

211 drained binder. Also, steel fibre, as a thermal conductor, may influence the bitumen

212 heating process and lead to more ageing of the bitumen during the draining process and

213 hence, lead to higher asphaltene content. The results suggest that the presence of

214 fibres leads to higher asphaltene content, however, due to the variability in the

$\mathbf{2 1 5}$ asphaltene test results, it is hard to draw conclusions about any differences. For this

$\mathbf{2 1 6}$ reason the rheological properties of the drained binders were evaluated by creating

$\mathbf{2 1 7}$ complex modulus master curves.

\section{4.3 Complex modulus master curve of base and drained binder}

219 Figure 5 shows the complex modulus master curves for base binder, drained base binder

220 and drained binder after mixing with fibres. A considerable difference in the complex

221 modulus values of drained binder after mixing with fibres, compared to both base and

222 drained base binder can be seen. This increase in complex modulus could be due to the

223 fibre affecting the chemical composition of the binder by adsorption/absorption of

224 different fractions, mainly lighter fractions. A previous study, using chromatography,

$\mathbf{2 2 5}$ indicated that the fibre could influence the absorption of different fractions, particularly

226 lighter fractions [26]. This result reflects the asphaltene content results, as the

$\mathbf{2 2 7}$ asphaltene content increased for drained binder after mixing with fibres, as shown in

228 Table 3. 
It is important to note that the complex modulus values of drained binder after mixing with glass and steel fibre were almost the same. Cellulose fibre showed higher complex modulus compared to other fibre types. This increase in complex modulus may be because cellulose fibre had lower drained binder percentage (Table 2), indicating retention of more of the bitumen.

\subsection{Pneumatic adhesion tensile testing instrument (PATTI)}

235 The PATTI test was used to measure the influence of fibres on mastic bond strength.

236 Three filler-bitumen ratios $(0.8,1.0$ and 1.2$)$ and three fibre contents $(0.5,1.0$ and

$2372.0 \%$ by bitumen volume) were used in this investigation. Failure strength results are

238 shown in Figures 6 to 8 and the mode of failure in Table 4, as illustrated in Figures 9 and

23910.

\section{$240 \quad$ 4.4.1 Influence of fibre content and type}

241 Three tests were performed for each mastic type, and the average tensile strength was

242 reported, as shown in Figures 6 to 8, where error bars represent plus and minus one

243 standard error (standard deviation divided by the square root of number of samples).

244 The tensile strengths of different fibre types and filler-bitumen ratios were reasonably

245 repeatable, indicating that the application of a constant rate of air pressure was

246 successful for these tests. The specimens exhibited a linear response to the increase in

$\mathbf{2 4 7}$ pressure until the pressure overcame the cohesive strength of the mastic or the

248 adhesive strength of the mastic-aggregate interface and then rapidly decreased to zero.

249 It can be seen that on average, all fibre types increased the pull-off tensile strength

250 compared to the base mastic. Table 5 gives the average results along with t-test results,

251 comparing fibre mastics to the base binder, for the three filler-bitumen ratios. Most fibre

252 percentages and types show statistically significant increases in the pull-off strength.

253 The glass-l fibre showed the highest increase in bond strength among all fibre types.

254 This increase may be due to two reasons. Firstly, glass fibre contains silicon dioxide

$255\left(\mathrm{SiO}_{2}\right)$ and aluminium oxide $\left(\mathrm{Al}_{2} \mathrm{O}_{3}\right)$. This chemical combination can form strong chemical

256 bonds with sulfoxides and carboxylic acids in bitumen [27, 28]. Secondly, glass fibre

257 dimensions (length and width) may help the fibres to cross over each other to form three

258 dimensional networks. These networks then provide support to the composite structure

259 by holding the components together and spreading stresses [29].

260 Base mastics with different filler-bitumen ratios showed cohesive failure (failure within

261 the mastic). The failure type changed from cohesive to hybrid (partly adhesive failure 
262 between aggregate and mastic) with an increase in the pull-off strength when 1.0 and

$2632.0 \%$ cellulose and glass-s fibres were used as a modification for 1.0 and 1.2 filler-

264 bitumen ratios. This implies an improvement in the cohesive strength of the mastic with 265 the increase in fibre content, as shown in Figures 7 and 8 . This behaviour may be

266 explained by the higher fibre content both mechanically stabilizing the material and/or

267 absorbing/adsorbing the bituminous binder (see Table 2) [30]. The latter is likely with

268 cellulose fibre since the surface texture of cellulose fibres comprises many interweaved

269 branches with non-uniform sizes and rough surfaces, which will increase the specific

270 surface area and hence the absorption/adsorption capability (see Table 1), as shown in

271 SEM images (see Figure 2). These features of cellulose fibre might explain the hybrid

272 failure at 0.8 filler-bitumen ratio for mastic modified by cellulose fibre, whereas other

273 fibre types exhibited a cohesive failure, as shown in Table 4 and Figure 9 a.

274 On the other hand, the longer steel and glass-I fibre samples showed a hybrid failure for

275 all fibre percentages at 1.0 and 1.2 filler-bitumen ratios. This could be due to the

276 dimensions of these fibres, leading to a more effective network and therefore enhanced

277 reinforcement effects.

\subsubsection{Influence of filler-bitumen ratio}

279 The results (Figures 6, 7 and 8) showed that the pull-off tensile strength increased with

280 the increase in the filler-bitumen ratio. A possible explanation for this might be that

281 adding more filler enhanced the interaction between the bitumen and the filler particles

282 [31]. Bituminous binders are non-polar, while molecules of limestone are more polar.

283 This may help to satisfy the energy demand of the aggregate surface by improving the

284 adhesion between the aggregate and the mastic [28, 32].

285 There is a decrease in the pull-off tensile strength of the 1.2 filler-bitumen ratios at

$2862.0 \%$ fibre content, particularly for cellulose, glass-l and steel fibres. This may indicate

$\mathbf{2 8 7}$ that adding more fibre with a high absorption/adsorption and/or large surface area led to

288 an increase in the percentage of voids in the matrix $[33,34]$. The stress applied to the

289 specimen may have been concentrated around these voids, and the fracture may have

290 begun at these points. Moreover, as the percentage of filler and fibre increased, the

291 composite became stiffer and was, therefore, more likely to show brittle behaviour. This

292 suggests that when adding more fibre and filler, there should be enough binder in the

293 mix to reduce the voids in the mastic.

294 It is important to note that the modulus and Poisson's ratio of steel and glass fibres are 295 very large compared to the matrix, and therefore a concentration of stress will occur at 296 the interface. Also, steel fibre has large thickness and according to previous studies, the 
stress concentration area depends on the fibre thickness and this area will increase as

298 fibre thickness increases [35] (see Figure 11).

\subsection{Surface energy}

300 The dynamic contact angle (DCA) measurement of bitumen was used in this study. The

301 contact angles were measured for each drained binder for each probe liquid, and the

302 contact angle was taken as the average of four or five replicates and the variation

303 between results was low, as shown in Table 6 . The results for the surface energy

304 components of the drained binders are shown in Table 7 in which $\gamma_{s}^{A B}$ represents the

305 polar surface energy component of the solid and $\gamma_{s}^{L W}$ represents the non-polar (Lifshitz-

306 van der Waals) surface energy component of the solid. The results for the surface energy

307 components of the drained binders showed more variation in the $\gamma_{s}^{A B}$ values than the $\gamma_{s}^{L W}$

308 values, ranging from 0.19 to $1.78 \mathrm{~mJ} / \mathrm{m}^{2}$, as shown in Table 7 . The results showed that

309 the bituminous binder molecular constituent forces are mainly Lifshitz-van der Waals

$\mathbf{3 1 0}$ (non-polar) in character [36].

311 The surface energy components of limestone aggregate were determined by using a

312 dynamic vapour sorption (DVS) approach, and the results are shown in Table 8. This

$\mathbf{3 1 3}$ method is usually used for high surface energy materials such as aggregate, and the

314 advantage of this method is that it takes into consideration the irregular shape and

315 surface texture of the aggregate [7]. The surface energy of limestone aggregate was

316 found to be $104.19 \mathrm{~mJ} / \mathrm{m}^{2}$.

\section{4.6 Work of cohesion and adhesion}

318 The results for work of cohesion ( $2 \gamma^{\text {total }}$ ) of the base drained binder and drained binder 319 after mixing with fibres are shown in Table 9. Table 4 shows the mode of failure in the

320 PATTI tests and reveals that the 0.8 filler-bitumen ratio mastics consistently failed by

321 fully cohesive failure. It is, therefore, interesting to compare the pull-off strength for

322 these mastics to the work of cohesion of the binders. The pull-off strengths are included

323 in Table 9 and Figure 12 shows a comparison between work of cohesion and pull-off

324 tensile strength. The work of cohesion results cover just a small range of values but it

325 was found that higher pull-off tensile strength corresponds to higher work of cohesion.

326 These results are consistent with data obtained in another recent study [8].

327 One consistent finding in this study is that all drained binders after mixing with fibres,

328 showed higher values for work of cohesion compared to that of the drained base binder.

329 Also, it is noted that all unmodified mastics showed a cohesive failure, while highly

330 modified mastics showed a hybrid failure (partially between aggregate and bitumen) 
331 together with an increase in pull-off strength. These observations indicate that adding

332 fibre increases the cohesive strength of the mastic leading to hybrid failure.

333 The work of adhesion results are shown in Table 10. It is interesting to note that drained

334 binder after mixing with cellulose fibre had the lowest value of work of adhesion. This is

335 due to the low value of the Lewis base parameter of surface free energy of the drained

336 binder after mixing with cellulose fibre. This finding may explain the hybrid failure for

337 mastic modified with cellulose fibre at 0.8 filler-bitumen ratio and 1.0 and $2.0 \%$ fibre,

338 while other modified mastics showed cohesive failure at this filler-bitumen ratio (see

339 Table 4). These surface energy results support the ability of the (PATTI) test to detect

340 differences in bond strength. However, none of the pull-off tensile strength samples

341 showed adhesive failure because pull-off tensile strength tests were done at room

342 temperature $\left(20^{\circ} \mathrm{C}\right)$ and in dry conditions. These conditions eliminate the possibility of

343 adhesive failure. Therefore, this study was not able to find a relationship between the

344 pull-off tensile strength and the work of adhesion.

\section{$345 \quad 4.7$ Conclusions}

346 This paper has examined the influence of fibres on bitumen mastic, based on pull-off

347 tensile strength, asphaltene content, surface energy measurement and scanning

348 electronic microscopy. The following conclusions are offered:

- Fibre asphalt mastics were observed using a scanning electron microscope (SEM). The formation of three-dimensional networks was observed for glass and steel fibre reinforced mastic.

- The drainage test results showed that cellulose fibre can retain more than $55 \%$ of binder. Other fibre types (glass and steel) can retain up to $30 \%$ of binder.

- All fibre types increased the asphaltene content and complex modulus of the drained binder compared to the base binder. However, the differences between asphaltene contents for different fibre types were too small to discriminate between them with confidence.

- Adding fibre led to an increased pull-off tensile strength of the mastics, at the same time changing the failure mode from cohesive to hybrid, implying an improvement in cohesive strength of the mastic.

o There was a general reduction in the pull-off tensile strength of the 1.2 filler bitumen ratio at high fibre content $(2.0 \%)$.

o The surface energy of drained binder after mixing with fibres was estimated by dynamic contact angle (DCA) measurements. The contact angle results for each 
drained binder varied within a narrow range, making this a useful test for characterising these materials.

o In general, there is a good agreement between work of the cohesion and pull-off tensile strength for 0.8 filler bitumen ratio and higher work of cohesion results in higher pull-off tensile strength where the mode of failure is cohesive. 
371 Table 1 Basic properties of fibres

\begin{tabular}{|c|c|c|c|c|c|}
\hline $\begin{array}{c}\text { Fibre } \\
\text { type }\end{array}$ & $\begin{array}{c}\text { Specific } \\
\text { density } \\
\left(\mathbf{g} / \mathbf{c m}^{\mathbf{3}} \mathbf{)}\right.\end{array}$ & Length $\mathbf{( \mu \mathbf { m } )}$ & $\begin{array}{c}\text { Width } \\
\mathbf{( \mu \mathbf { m } )}\end{array}$ & $\begin{array}{c}\text { Modulus of } \\
\text { elasticity at } \\
\mathbf{2 3} \mathbf{~} \mathbf{C}(\mathbf{G P a})\end{array}$ & $\begin{array}{c}\text { Specific } \\
\text { surface } \\
\text { area } \\
\left(\mathbf{m}^{\mathbf{2} / \mathbf{g})}\right.\end{array}$ \\
\hline Cellulose & 1.50 & 20 to 2,500 & 25 & - & 138.53 \\
\hline Glass-s & 2.58 & 6,000 & 12 to 20 & 80.3 & 8.85 \\
\hline Glass-I & 2.58 & 13,000 & 12 to 20 & 80.3 & 14.36 \\
\hline Steel & 7.85 & 4,000 to 12,000 & 180 to 300 & $210 *$ & - \\
\hline
\end{tabular}

*Standard steel fibre modulus

Table 2 Results of binder drainage test (basket method)

\begin{tabular}{|c|c|c|c|}
\hline Fibre type & $\begin{array}{c}\text { Percent of drained } \\
\text { material (average of three } \\
\text { results) }(\%)\end{array}$ & $\begin{array}{c}\text { Coefficient of } \\
\text { variation (\%) }\end{array}$ & Standard error \\
\hline Base binder & 97.0 & 0.7 & 0.41 \\
\hline Cellulose & 43.4 & 3.0 & 0.74 \\
\hline Glass-s & 74.9 & 2.2 & 0.96 \\
\hline Glass-I & 71.1 & 2.4 & 0.97 \\
\hline Steel & 72.1 & 1.2 & 0.49 \\
\hline
\end{tabular}

376 Table 3 Asphaltene content test results

\begin{tabular}{|l|c|c|c|}
\hline \multicolumn{1}{|c|}{ Binder type } & $\begin{array}{c}\text { Asphaltene } \\
\text { content } \mathbf{( \% )}\end{array}$ & $\begin{array}{c}\text { Coefficient of } \\
\text { variation (\%) }\end{array}$ & Standard error \\
\hline Base binder & 12.7 & 1.1 & 0.10 \\
\hline Drained base binder & 14.7 & 0.5 & 0.05 \\
\hline Drained cellulose & 15.9 & 3.3 & 0.26 \\
\hline Drained glass-s & 14.9 & 4.0 & 0.57 \\
\hline Drained glass-I & 15.7 & 5.1 & 0.46 \\
\hline Drained steel & 15.5 & 5.0 & 0.55 \\
\hline
\end{tabular}


379 Table 4 Failure mode in fibre modified asphalt mastic

\begin{tabular}{|c|c|c|c|c|c|}
\hline \multirow[t]{2}{*}{ Mastic type } & \multirow[t]{2}{*}{ f/b* } & \multicolumn{4}{|c|}{ Failure type } \\
\hline & & $0.0 \%$ vol. & $0.5 \%$ vol. & $1.0 \%$ vol. & $2.0 \% \mathrm{vol}$. \\
\hline \multirow[t]{3}{*}{ Base mastic } & 0.8 & Cohesion & - & - & - \\
\hline & 1.0 & Cohesion & - & - & - \\
\hline & 1.2 & Cohesion & - & - & - \\
\hline \multirow{3}{*}{$\begin{array}{c}\text { Cellulose fibre } \\
\text { mastic }\end{array}$} & 0.8 & - & Cohesion & Hybrid & Hybrid \\
\hline & 1.0 & - & Cohesion & Hybrid & Hybrid \\
\hline & 1.2 & - & Cohesion & Hybrid & Hybrid \\
\hline \multirow{3}{*}{$\begin{array}{c}\text { Glass-s fibre } \\
\text { mastic }\end{array}$} & 0.8 & - & Cohesion & Cohesion & Cohesion \\
\hline & 1.0 & - & Cohesion & Hybrid & Hybrid \\
\hline & 1.2 & - & Cohesion & Hybrid & Hybrid \\
\hline \multirow{3}{*}{$\begin{array}{c}\text { Glass-I fibre } \\
\text { mastic }\end{array}$} & 0.8 & - & Cohesion & Cohesion & Cohesion \\
\hline & 1.0 & - & Hybrid & Hybrid & Hybrid \\
\hline & 1.2 & - & Hybrid & Hybrid & Hybrid \\
\hline \multirow{3}{*}{$\begin{array}{l}\text { Steel fibre } \\
\text { mastic }\end{array}$} & 0.8 & - & Cohesion & Cohesion & Cohesion \\
\hline & 1.0 & - & Hybrid & Hybrid & Hybrid \\
\hline & 1.2 & - & Hybrid & Hybrid & Cohesion \\
\hline
\end{tabular}


383 Table 5 Pull-off tensile strength t-test results

\begin{tabular}{|c|c|c|c|c|c|}
\hline $\begin{array}{c}\text { f/b } \\
\text { ratio* }\end{array}$ & Fibre & $\begin{array}{l}\text { Mean } \\
(\mathrm{MPa})\end{array}$ & t-stat & p-value & Significant** \\
\hline \multirow[t]{13}{*}{0.8} & Base mortar & 1.19 & - & - & - \\
\hline & $0.5 \%$ Glass-s & 1.61 & 4.828 & 0.0202 & Yes \\
\hline & $0.5 \%$ Glass-I & 1.71 & 5.677 & 0.0054 & Yes \\
\hline & $0.5 \%$ Cellulose & 1.56 & 4.121 & 0.0271 & Yes \\
\hline & $0.5 \%$ Steel & 1.44 & 2.731 & 0.0359 & Yes \\
\hline & $1 \%$ Glass-s & 1.76 & 4.139 & 0.0072 & Yes \\
\hline & $1 \%$ Glass-I & 1.78 & 6.394 & 0.0038 & Yes \\
\hline & $1 \%$ Cellulose & 1.64 & 4.703 & 0.0091 & Yes \\
\hline & $1 \%$ Steel & 1.76 & 4.117 & 0.0073 & Yes \\
\hline & $2 \%$ Glass-s & 1.85 & 6.403 & 0.0038 & Yes \\
\hline & 2\% Glass-I & 1.95 & 8.388 & 0.0069 & Yes \\
\hline & $2 \%$ Cellulose & 1.84 & 6.348 & 0.0039 & Yes \\
\hline & $2 \%$ Steel & 1.81 & 6.275 & 0.0041 & Yes \\
\hline \multirow[t]{13}{*}{1.0} & Base mortar & 1.25 & - & - & \\
\hline & $0.5 \%$ Glass-s & 1.61 & 3.775 & 0.0317 & Yes \\
\hline & $0.5 \%$ Glass-I & 1.78 & 3.350 & 0.0393 & Yes \\
\hline & $0.5 \%$ Cellulose & 1.69 & 4.525 & 0.0101 & Yes \\
\hline & $0.5 \%$ Steel & 1.55 & 3.641 & 0.0339 & Yes \\
\hline & $1 \%$ Glass-s & 1.78 & 3.798 & 0.0160 & Yes \\
\hline & $1 \%$ Glass-I & 2.06 & 5.222 & 0.0068 & Yes \\
\hline & $1 \%$ Cellulose & 1.76 & 6.398 & 0.0038 & Yes \\
\hline & $1 \%$ Steel & 1.88 & 5.446 & 0.0060 & Yes \\
\hline & $2 \%$ Glass-s & 2.10 & 8.518 & 0.0017 & Yes \\
\hline & $2 \%$ Glass-I & 2.16 & 8.794 & 0.0015 & Yes \\
\hline & $2 \%$ Cellulose & 2.09 & 11.947 & 0.0034 & Yes \\
\hline & $2 \%$ Steel & 1904 & 10.204 & 0.0047 & Yes \\
\hline \multirow[t]{13}{*}{1.2} & Base mortar & 1.72 & - & - & \\
\hline & $0.5 \%$ Glass-s & 1.93 & 2.174 & 0.0808 & No \\
\hline & $0.5 \%$ Glass-I & 2.08 & 4.087 & 0.0274 & Yes \\
\hline & $0.5 \%$ Cellulose & 1.99 & 3.410 & 0.0907 & No \\
\hline & $0.5 \%$ Steel & 2.00 & 2.617 & 0.0601 & No \\
\hline & $1 \%$ Glass-s & 2.03 & 2.372 & 0.0705 & No \\
\hline & $1 \%$ Glass-I & 2.47 & 7.338 & 0.0090 & Yes \\
\hline & $1 \%$ Cellulose & 2.10 & 3.353 & 0.0219 & Yes \\
\hline & $1 \%$ Steel & 2.12 & 3.242 & 0.0238 & Yes \\
\hline & $2 \%$ Glass-s & 2.06 & 2.368 & 0.0493 & Yes \\
\hline & $2 \%$ Glass-I & 2.17 & 4.786 & 0.0204 & Yes \\
\hline & $2 \%$ Cellulose & 2.06 & 4.316 & 0.0724 & No \\
\hline & 2\% Steel & 2.05 & 3.405 & 0.0764 & No \\
\hline
\end{tabular}

$384 * f / b$ : filler-bitumen ratio.

$385 * *$ indicates significant at the 95 percent confidence interval. 
Table 5 Contact angle measurement of bitumen binder

\begin{tabular}{|c|c|c|c|c|c|c|}
\hline & \multicolumn{2}{|c|}{$\begin{array}{c}\text { Contact Angle in } \\
\text { Diiodomethane }\end{array}$} & \multicolumn{2}{c|}{$\begin{array}{c}\text { Contact Angle in } \\
\text { Glycerol }\end{array}$} & \multicolumn{2}{c|}{$\begin{array}{c}\text { Contact angle in } \\
\text { Water }\end{array}$} \\
\hline Sample & Average ( $\left.{ }^{\circ}\right)$ & $\begin{array}{c}\text { CV* } \\
(\%)\end{array}$ & Average $\left({ }^{\circ}\right)$ & CV (\%) & Average ( $\left.{ }^{\circ}\right)$ & CV (\%) \\
\hline $\begin{array}{c}\text { Drained base } \\
\text { binder }\end{array}$ & 82.99 & 1.05 & 92.12 & 1.18 & 101.54 & 0.52 \\
\hline $\begin{array}{c}\text { Drained } \\
\text { cellulose }\end{array}$ & 80.23 & 1.32 & 92.56 & 0.08 & 101.58 & 1.36 \\
\hline $\begin{array}{c}\text { Drained glass-s } \\
\text { Drained glass-I }\end{array}$ & 78.22 & 2.69 & 94.26 & 1.08 & 95.32 & 1.19 \\
\hline Drained steel & 79.58 & 1.36 & 94.96 & 0.33 & 98.09 & 0.67 \\
\hline
\end{tabular}

${ }^{*} \mathrm{CV}$ : coefficient of variation

Table 6 Surface energy components of drained binder

\begin{tabular}{|l|c|c|c|}
\hline \multicolumn{1}{|c|}{ Binder type } & $\gamma_{\boldsymbol{s}}^{\boldsymbol{L W}}$ & $\boldsymbol{\gamma}_{\boldsymbol{s}}^{\boldsymbol{A B}}=2 \sqrt{\boldsymbol{\gamma}^{+} \boldsymbol{\gamma}^{-}}$ & $\boldsymbol{\gamma}^{\text {total }}\left(\mathbf{m} \mathbf{J} / \mathbf{m}^{\mathbf{2}}\right)$ \\
\hline Drained base binder & 15.99 & 1.78 & 17.77 \\
\hline Drained cellulose & 17.38 & 1.30 & 18.68 \\
\hline Drained glass-s & 18.41 & 0.46 & 18.88 \\
\hline Drained glass-I & 19.59 & 0.59 & 20.18 \\
\hline Drained steel & 17.71 & 0.19 & 17.90 \\
\hline
\end{tabular}

Table 7 Surface energy components of limestone aggregate

\begin{tabular}{|c|c|c|c|}
\hline Aggregate & $\gamma_{s}^{L W}$ & $\gamma_{s}^{A B}=2 \sqrt{\gamma^{+} \gamma^{-}}$ & $\gamma^{\text {total }}\left(\mathbf{m J} / \mathbf{m}^{2}\right)$ \\
\hline Limestone & 65.81 & 38.38 & 104.19 \\
\hline
\end{tabular}

Table 8 Work of cohesion ( $\left.2 y^{\text {total }}\right)$ and pull-off tensile strength values ( 0.8 filler-bitumen ratio)

\begin{tabular}{|l|c|c|}
\hline Sample & $\begin{array}{c}\text { Pull-off tensile } \\
\text { strength (MPa) } \mathbf{0 . 8} \\
\mathbf{f} / \mathbf{b} \text { ratio }\end{array}$ & $\begin{array}{c}\text { Work of cohesion } \\
\left(\mathbf{m} \mathbf{j} / \mathbf{m}^{\mathbf{2}} \mathbf{)}\right.\end{array}$ \\
\hline Drained base binder & 1.19 & 35.53 \\
\hline Drained cellulose & 1.84 & 37.35 \\
\hline Drained glass-s & 1.85 & 37.76 \\
\hline Drained glass-I & 1.95 & 40.36 \\
\hline Drained steel & 1.81 & 35.80 \\
\hline
\end{tabular}


405 Table 9 Work of adhesion results

\begin{tabular}{|l|c|}
\hline \multicolumn{1}{|c|}{ Sample } & $\begin{array}{c}\text { Work of adhesion } \\
\left(\mathbf{m} \mathbf{j} / \mathbf{m}^{\mathbf{2}} \mathbf{)}\right.\end{array}$ \\
\hline Drained base binder & 122.69 \\
\hline Drained cellulose & 125.18 \\
\hline Drained glass-s & 172.88 \\
\hline Drained glass-I & 158.64 \\
\hline Drained steel & 163.21 \\
\hline
\end{tabular}

406

407 

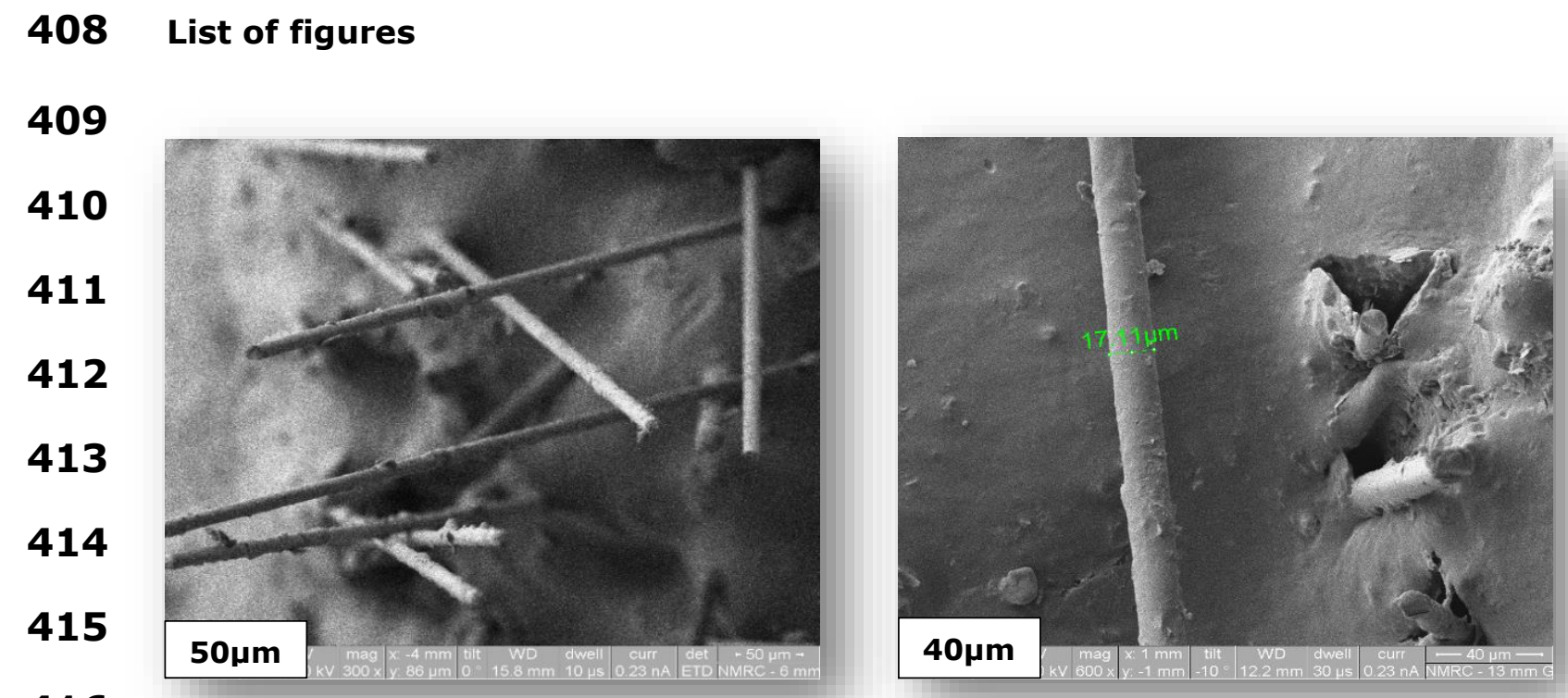

416

417

Figure 1 SEM images of glass fibre modified asphalt mastics
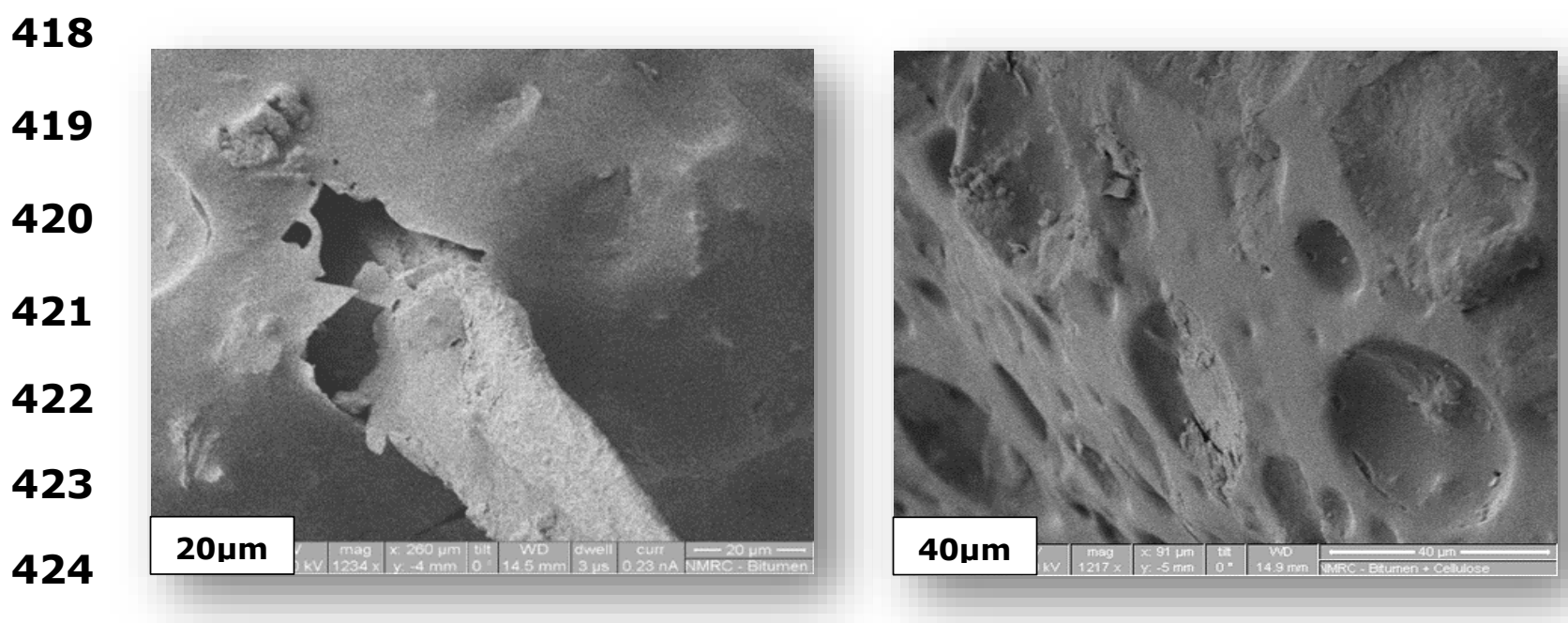

425

Figure 2 SEM images of cellulose fibre modified asphalt mastics

426 


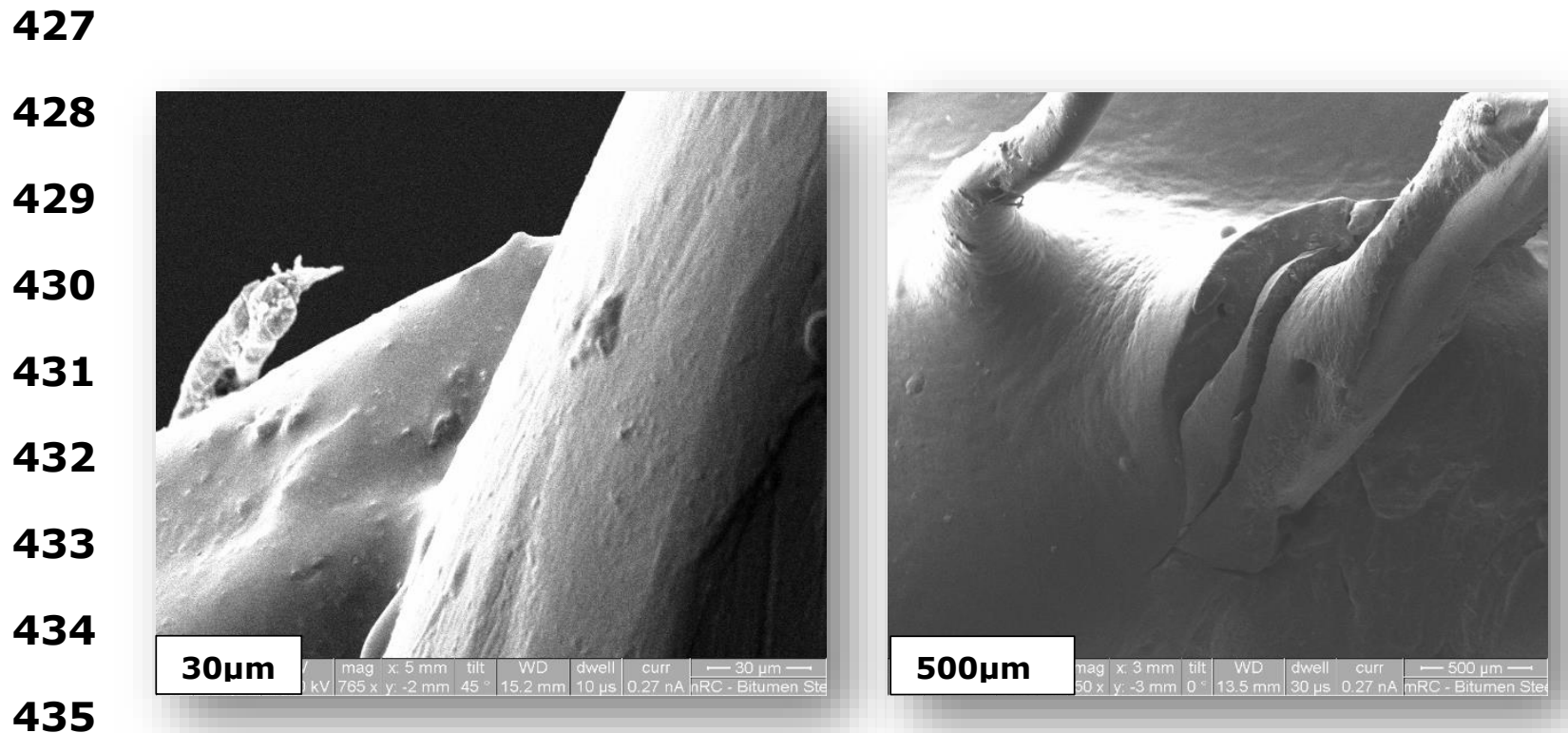

436

Figure 3 SEM images of steel fibre modified asphalt mastics

437

438

439

440

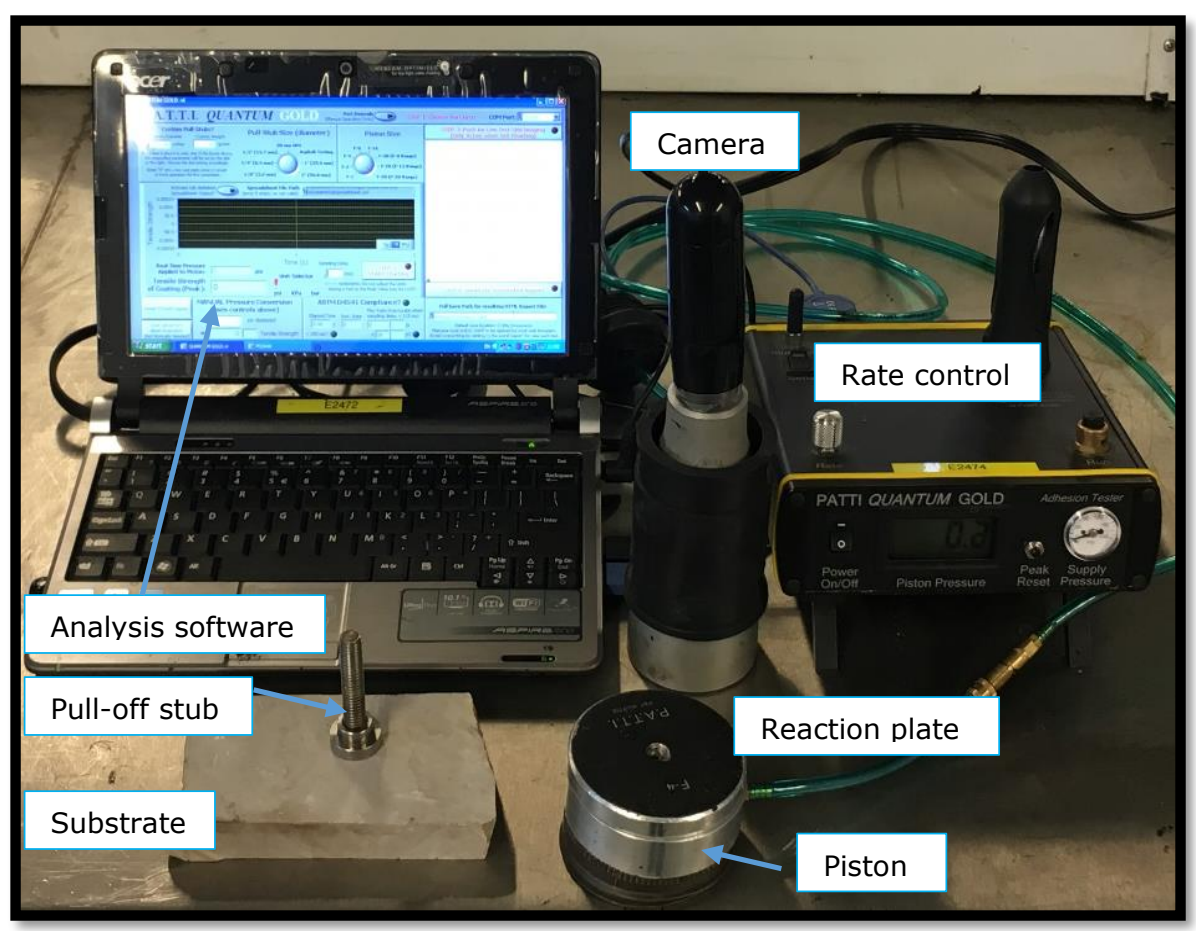

Figure 4 General representation of PATTI test [17] 


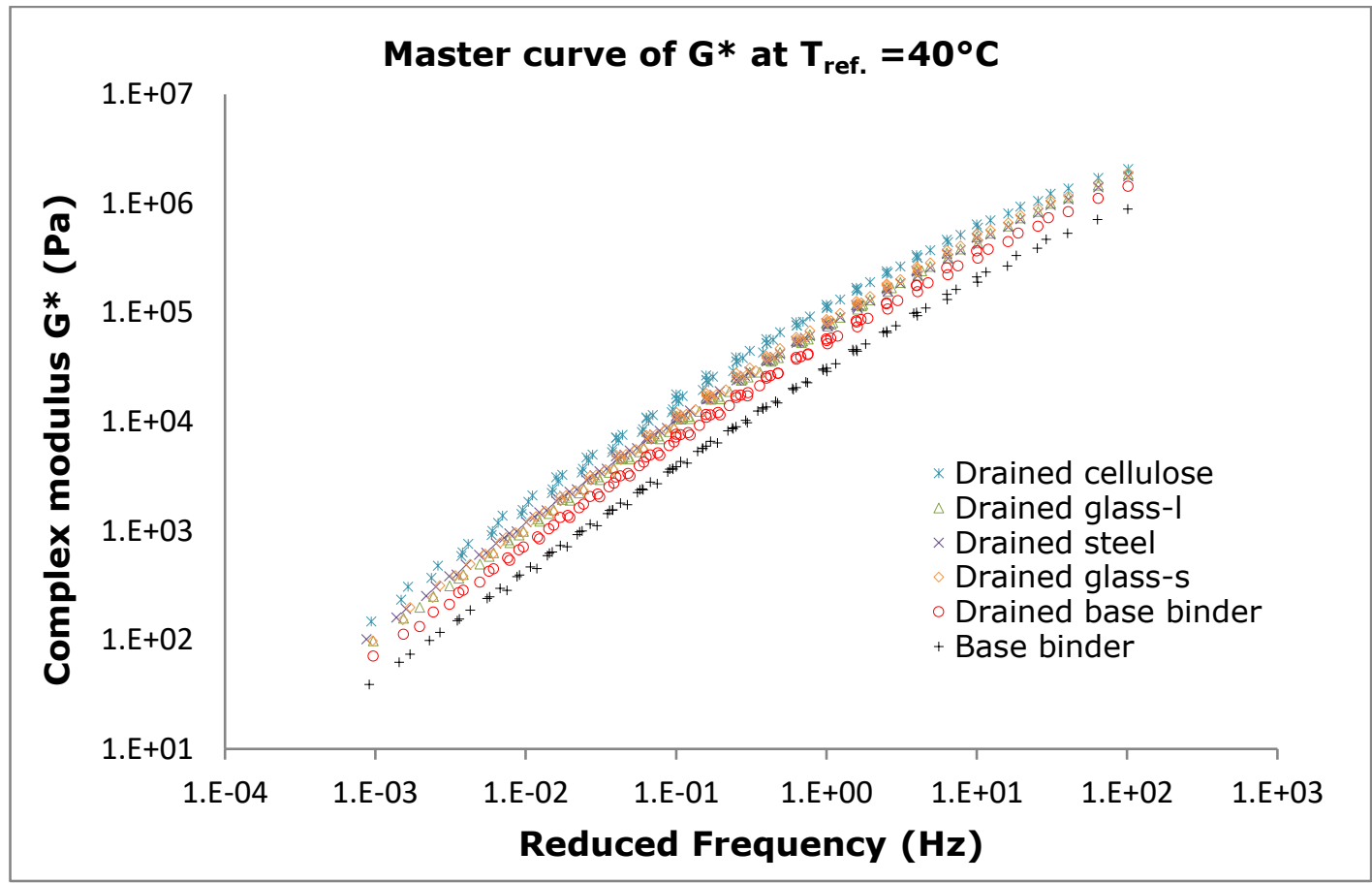

443 Figure 5 Complex modulus master curves for drained binders (2.0\% fibre by volume)

\section{4}

445

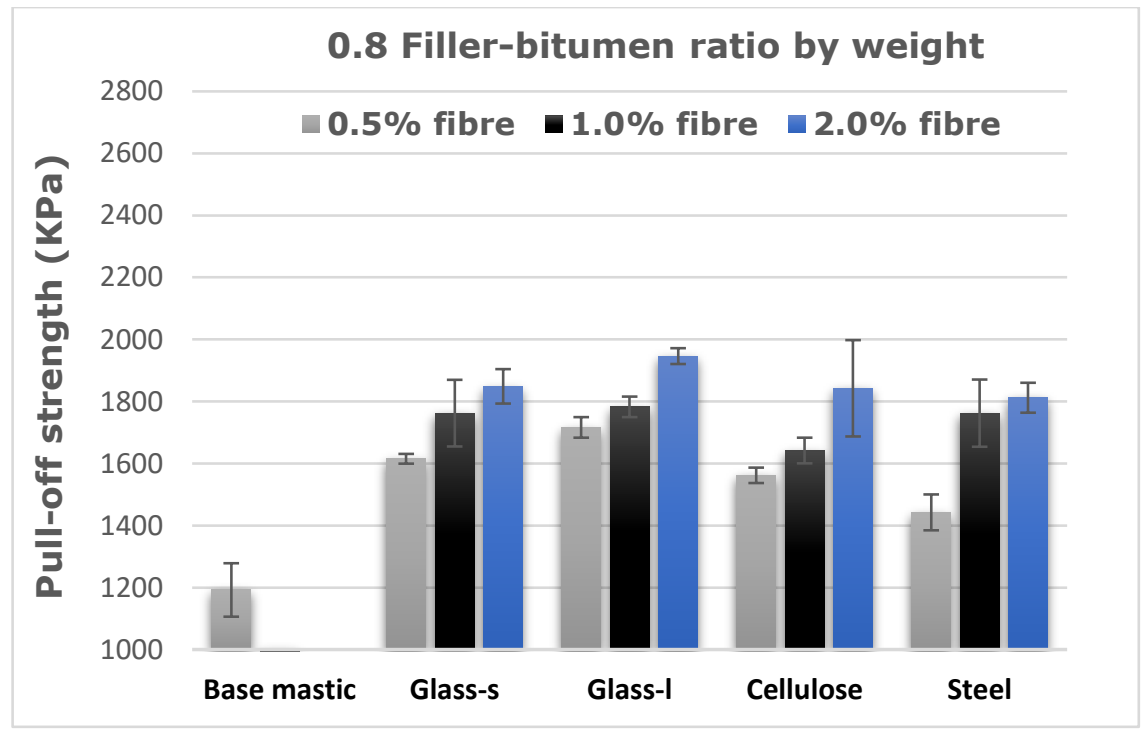

446

Figure 6 Pull-off tensile strength of base and modified mastics 


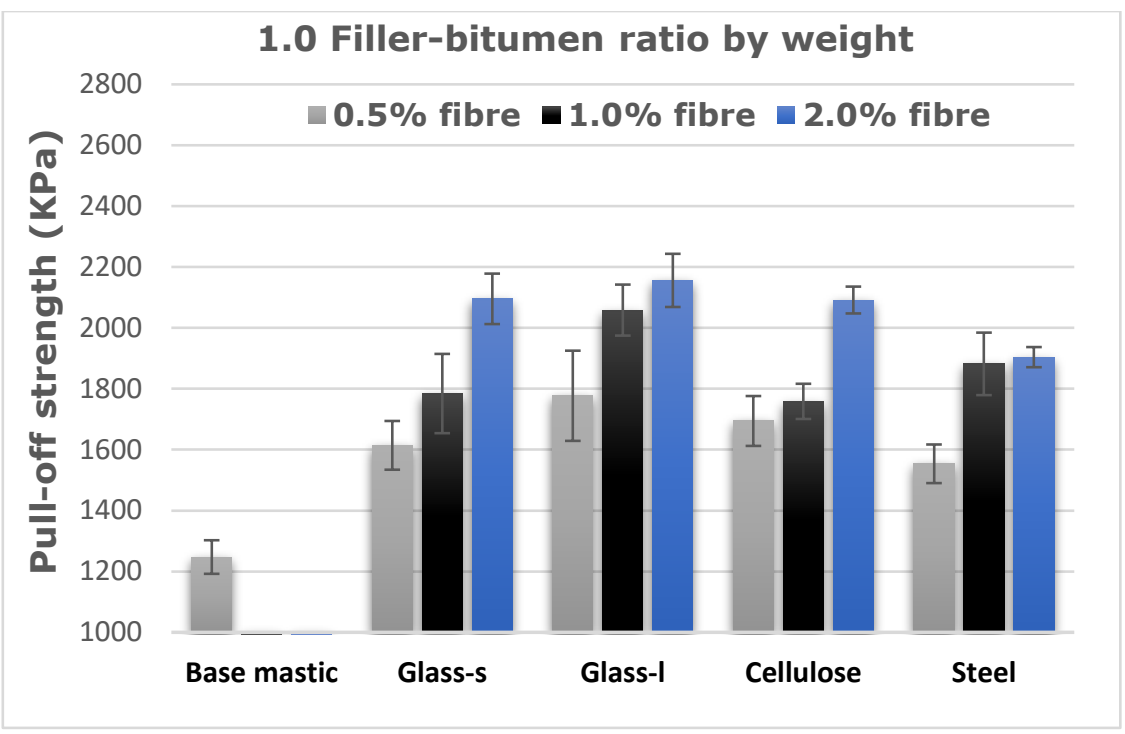

449

Figure 7 Pull-off tensile strength of base and modified mastics

450

451

452

453

454

455

456

457

458

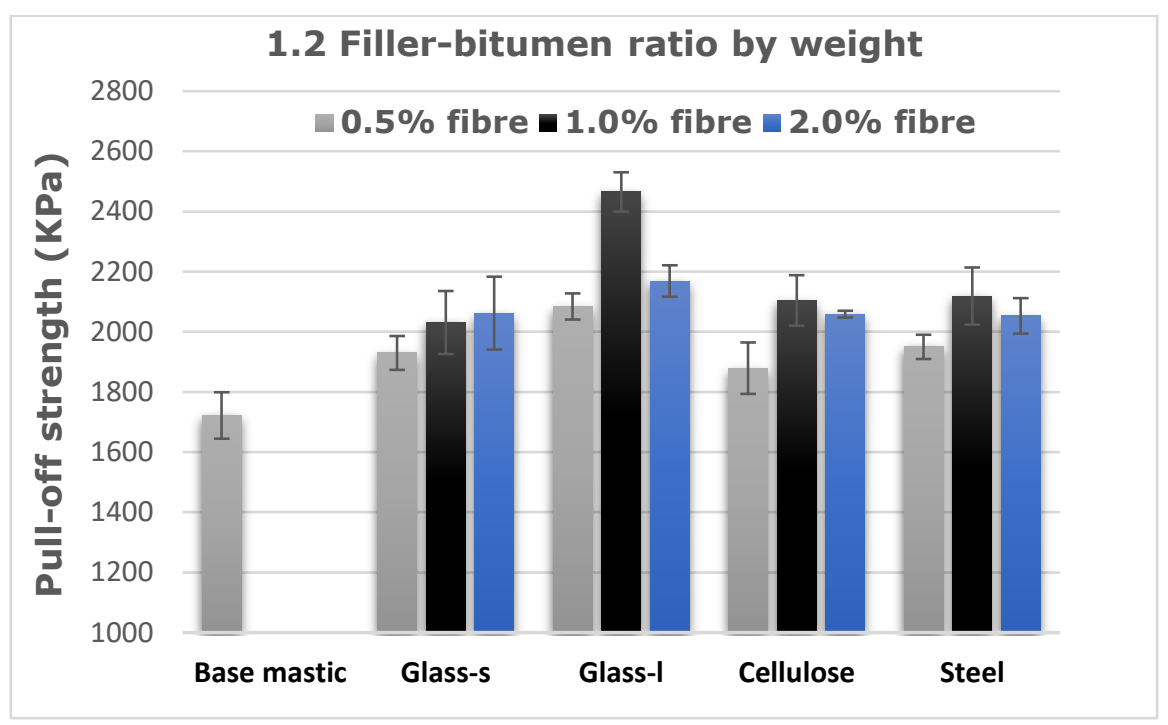

Figure 8 Pull-off tensile strength of base and modified mastics 
459

460
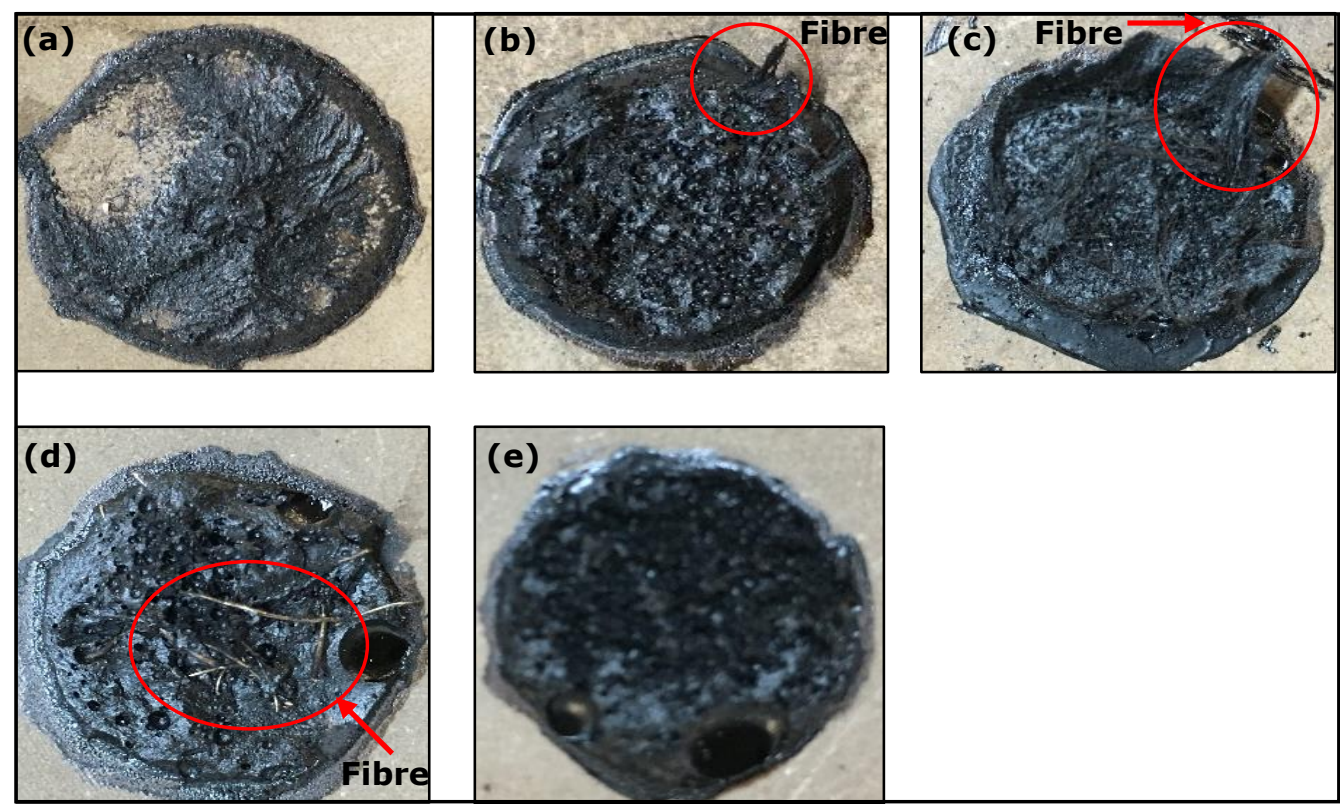

461

Figure 9 Failure surfaces of 0.8 filler bitumen ratio asphalt mastic with limestone

462 aggregate with different fibre types: (a) cellulose, (b) glass-s, (c) glass-l, (d) steel and 463

(e) base mastic.

465 
467
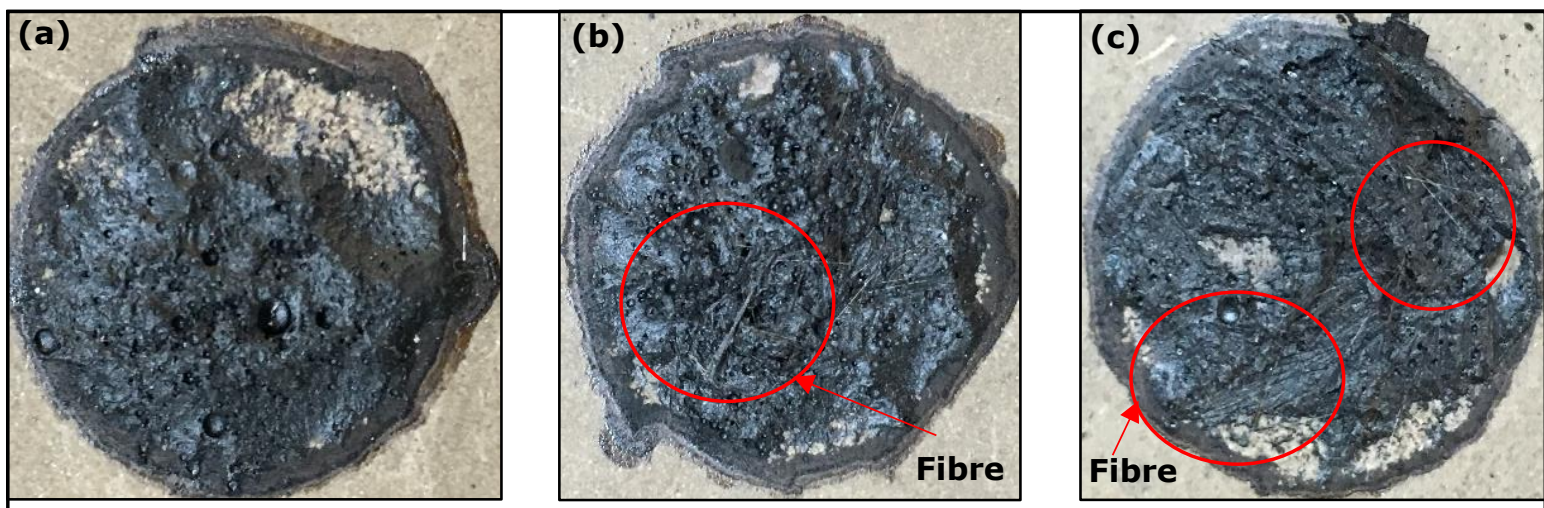

468
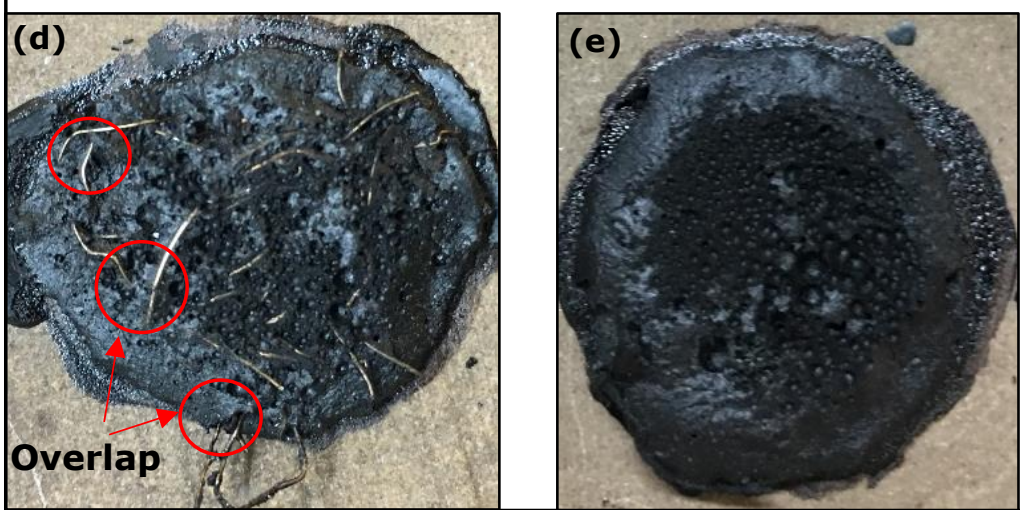

Figure 10 Failure surfaces of 1.2 filler bitumen ratio asphalt mastic with limestone

469

470

471

472

473

474

475

476

477

478

479

480

481

482 aggregate with different fibre types: (a) cellulose, (b) glass-s, (c) glass-I, (d) steel and

(e) base mastic.
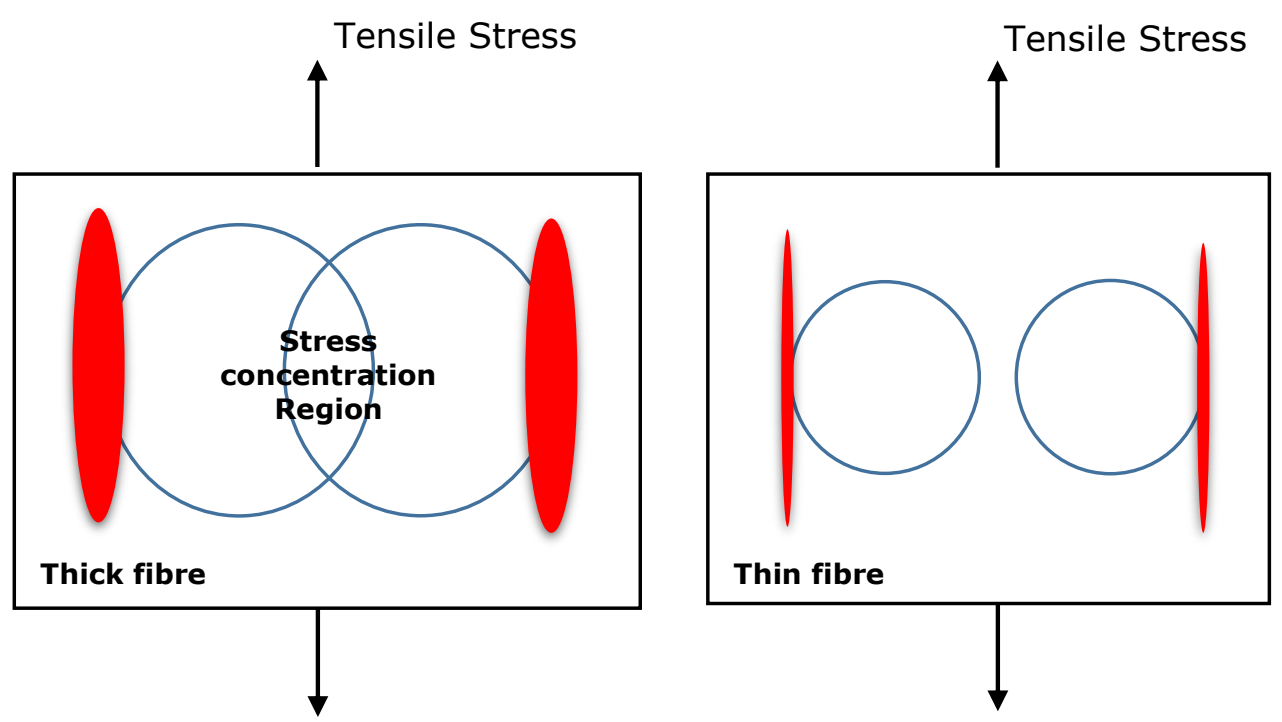

Figure 11 Stress concentration due to fibre size [35] 


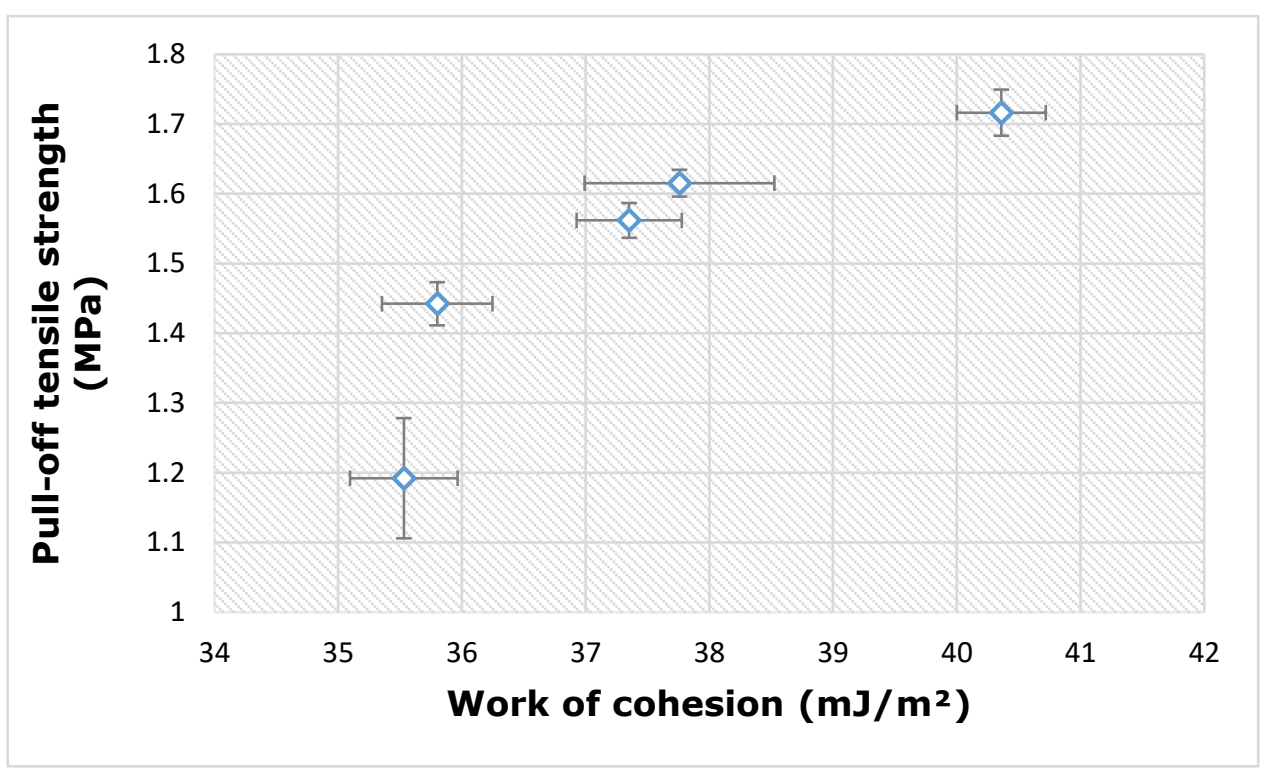

Figure 12 Comparison between work of cohesion of drained binders and pull-off tensile strength of 0.8 filler-bitumen ratio mastics (specimens undergoing cohesive failure)

487

\section{Acknowledgment}

489 The authors would like to acknowledge the financial support from the Higher 490 Committee for Education Development in Iraq. The authors acknowledge the 491 support provided by the Nottingham Transportation Engineering Centre (NTEC) at the University of Nottingham, United Kingdom. The authors thank the Nanoscale and Microscale Research Centre ( $n$ mRC) at the University of Nottingham, United Kingdom for providing access to instrumentation and $\mathrm{Dr}$ Christopher D. J. Parmenter for technical assistance. 
501 [1] L. Mo, Damage development in the adhesive zone and mortar 502 of porous asphalt concrete, TU Delft, Delft University of

503 Technology, 2010.

504 [2] S. Caro, E. Masad, A. Bhasin, D. Little, Coupled

505

506

507 micromechanical model of moisture-induced damage in asphalt mixtures, Journal of Materials in Civil Engineering 22(4) (2009) 380-388.

508

509

[3] M.I. Hossain, R.A. Tarefder, Behavior of asphalt mastic films under laboratory controlled humidity conditions, Construction and Building Materials 78 (2015) 8-17.

511 [4] D.-W. Cho, K. Kim, The mechanisms of moisture damage in 512 asphalt pavement by applying chemistry aspects, KSCE Journal of 513 Civil Engineering 14(3) (2010) 333-341.

514 [5] K. Kanitpong, H.U. Bahia, Role of adhesion and thin film 515 tackiness of asphalt binders in moisture damage of HMA, 516 Association of Asphalt Paving Technologists Technical Sessions, 517 2003, Lexington, Kentucky, USA, 2003.

518 [6] A. Copeland, J. Youtcheff, N. Kringos, A. Scarpas, S. 519 Mahadevan, Determination of bond strength as a function of 520 moisture content at the aggregate-mastic interface, 10th International Conference on Asphalt Pavements-August 12 to 17, 2006, Quebec City, Canada, 2006.

524

[7] N. Ahmad, Asphalt mixture moisture sensitivity evaluation using surface energy parameters, University of Nottingham, 2011.

525

526

527

528

529

[8] R. Moraes, R. Velasquez, H. Bahia, Using bond strength and surface energy to estimate moisture resistance of asphaltaggregate systems, Construction and Building Materials 130 (2017) 156-170.

532

[9] Z. Chen, S.-p. Wu, Z.-h. Zhu, J.-s. Liu, Experimental evaluation on high temperature rheological properties of various fiber modified asphalt binders, Journal of Central South University of Technology 15 (2008) 135-139.

535

[10] M. Mohammed, T. Parry, J. Grenfell, Fibre behaviour and influence on the properties of asphalt mortar, Bearing Capacity of Roads, Railways and Airfields (2017). 
[11] J. Serfass, J. Samanos, Fiber-modified asphalt concrete characteristics, applications and behavior (with discussion), Journal of the Association of Asphalt Paving Technologists 65 539 (1996).

540 [12] H. Chen, Q. Xu, S. Chen, Z. Zhang, Evaluation and design of 541 fiber-reinforced asphalt mixtures, Materials \& Design 30(7) 542 (2009) 2595-2603.

543 [13] A. Mahrez, M.R. Karim, H.Y.b. Katman, Fatigue and deformation properties of glass fiber reinforced bituminous mixes, Journal of the Eastern Asia Society for Transportation Studies 6 546 (2005) 997-1007.

547 [14] European Committee for Standardization, 1426: Bitumen and 548 bituminous binders-determination of needle penetration, British 549 Standards (2007).

550 [15] European Committee for Standardization, Bituminous mixtures - Test methods for hot mix asphalt - Part 18: Binder drainage, basket method, British Standard, 2004, pp. 5-10.

[16] British Standards, Part 143. Determination of asphaltenes (heptane insolubles) in crude petroleum and petroleum products, The institute of peteroleum and BSI 1996, London, 2000.

556

[17] D. ASTM, 4541, Standard Test Method for Pull-Off Strength of Coatings Using Portable Adhesion Testers, ASTM International: West Conshohocken, PA (2002).

559 [18] Mittal. K. L, Handbook of Adhesive Technology Second 560 Edition, Revised and Expanded ed., Taylor \& Francis Group, LLC, 561 United States of America, 2003.

562 [19] D.N. Little, A. Bhasin, Using surface energy measurements to 563 select materials for asphalt pavement, NCHRP Project 9-37, 2006.

564 [20] E.A. Masad, C. Zollinger, R. Bulut, D.N. Little, R.L. Lytton, 565 Characterization of HMA moisture damage using surface energy and fracture properties (with discussion), Journal of the

568 [21] C. Van Oss, M. Chaudhury, R. Good, Monopolar surfaces, 569 Advances in colloid and interface science 28 (1987) 35-64.

570 [22] P. Reynolds, T. Cosgrove, Colloid Science-Principles, 571 Methods, and Applications, Blackwell Publishing Ltd, 2005. 
[23] A. Bhasin, Development of methods to quantify bitumenaggregate adhesion and loss of adhesion due to water, Texas A\&M

574 University, 2006.

575 [24] L. Oyekunle, Influence of chemical composition on the 576 physical characteristics of paving asphalts, Petroleum Science and 577 Technology 25(11) (2007) 1401-1414.

578 [25] F. Canestrari, F. Cardone, A. Graziani, F.A. Santagata, H.U. 579 Bahia, Adhesive and cohesive properties of asphalt-aggregate 580 systems subjected to moisture damage, Road Materials and 581 Pavement Design 11(sup1) (2010) 11-32.

582 [26] B.J. Putman, Effects of fiber finish on the performance of 583 asphalt binders and mastics, Advances in Civil Engineering 2011 584 (2011).

585

586

587

588

589

590

591

592

593

594

595

596

[27] J. Zhang, G.D. Airey, J.R. Grenfell, Experimental evaluation of cohesive and adhesive bond strength and fracture energy of bitumen-aggregate systems, Materials and Structures (2015) 115.

[28] R. Moraes, R. Velasquez, H. Bahia, Measuring the effect of moisture on asphalt-aggregate bond with the bitumen bond strength test, Transportation Research Record: Journal of the Transportation Research Board (2209) (2011) 70-81.

[29] S. Tapkın, A. Cevik, U. Usar, Prediction of Marshall test results for polypropylene modified dense bituminous mixtures using neural networks, Expert Systems with Applications 37(6) (2010) 4660-4670.

599 [31] A.F. Faheem, H.U. Bahia, Modelling of asphalt mastic in terms 600 of filler-bitumen interaction, Road Materials and Pavement Design 601 11(sup1) (2010) 281-303.

602 [32] R.G. Hicks, Moisture damage in asphalt concrete, 603 Transportation Research Board1991.

604 [33] K.W. Kim, Y.S. Doh, S. Lim, Mode I reflection cracking 605 resistance of strengthened asphalt concretes, Construction and 606 Building Materials 13(5) (1999) 243-251. 
607 [34] S. Tapkın, U. Usar, A. Tuncan, M. Tuncan, Repeated creep 608 behavior of polypropylene fiber-reinforced bituminous mixtures, 609 Journal of Transportation Engineering 135(4) (2009) 240-249.

610 [35] J.-S. Chen, K.-Y. Lin, Mechanism and behavior of bitumen 611 strength reinforcement using fibers, Journal of Materials Science $61240(1)(2005)$ 87-95.

613 [36] A.W. Hefer, Adhesion in bitumen-aggregate systems and 614 quantification of the effect of water on the adhesive bond, Texas 615 A\&M University, 2005.

616

617 